\title{
In situ Formation of Zinc Oxide on Bamboo Bleached Pulp in Preparation of Antibacterial Paper: Effect of Precursors Addition
}

\author{
Zakiah Sobri, ${ }^{\mathrm{a}}$ Ainun Zuriyati Mohamed Asa'ari, ${ }^{\mathrm{a}, *}$ Norzita Yacob, ${ }^{\mathrm{b}}$ Paik San H'ng, ${ }^{\mathrm{a}}$ \\ Luqman Chuah Abdullah, ${ }^{\mathrm{a}}$ and Edi Syams Zainudin ${ }^{\mathrm{c}, *}$
}

\begin{abstract}
An approach of green in situ synthesis single-step method was applied to produce antibacterial paper. The objective was to investigate the effect of precursor addition on the formation of zinc oxide particles using an in situ single-step method. Zinc chloride concentrations of $0.1,0.3,0.5$, and 0.7 $M$ were prepared and added into a solution of algae extract and bamboo pulp. The prepared pulps were tested and made into handsheets using a papermaking machine based on TAPPI T205 (2006). Morphological observation of treated papers was conducted using a field emission scanning electron microscope (FESEM). An average of 400 to $570 \mathrm{~nm}$ zinc oxide spherical-shaped particle was observed on the fibers of paper. The percentage of element composition of the treated paper were $15.08 \%$ to $34.08 \%$ of zinc and $17.45 \%$ to $32.59 \%$ of oxygen captured via scanning electron microscopy with energy dispersive X-ray (SEM-EDX) analysis. The crystallinity test was performed using X-ray dispersion (XRD). A higher percentage of precursors exhibited a more amorphous structure. A measurement of more than $30 \%$ increment of inhibition zone was obtained from 10.00 to $25.00 \mathrm{~mm}$ against $S$. aureus, S. choleraesuis, and E. coli. Precursors addition of more than $0.3 \mathrm{M}$ would have the most potential to enhance the growth of zinc oxide via in situ preparation, hence providing better antibacterial properties of the prepared papers.
\end{abstract}

Keywords: Algae; Zinc oxide; Bamboo; Bleached pulp; In situ preparation; Papermaking

Contact information: a: Pulp and Paper \& Pollution Control Program, Laboratory of Biopolymer and Derivatives, Institute of Tropical Forestry and Forest Products (INTROP), Universiti Putra Malaysia, 43400 UPM Serdang, Selangor, Malaysia; b: Malaysian Nuclear Agency, Bangi 43000 Kajang, Selangor, Malaysia; c: Laboratory of Biocomposites, Institute of Tropical Forestry and Forest Products, Universiti Putra Malaysia, 43400 UPM Serdang, Selangor, Malaysia;

*Corresponding authors: ainunzuriyati@upm.edu.my; edisyam@upm.edu.my

\section{INTRODUCTION}

Zinc oxide is a multifunctional mineral due to its physical and chemical properties. It exists as a mineral named zincite and has been commercially synthesized for commercial purpose (Mirzaei and Darroudi 2017). Its non-toxicity and compatibility to human skin has placed zinc oxide in a wide range of applications such as in pharmaceuticals (Pronin et al. 2014), paints (Osmond 2019), textiles (Rajendra et al. 2010; Belay et al. 2020), and the electronic industries (Balogun et al. 2020). Among all material particles, zinc oxide is well known for having the most varied particle structures (Kołodziejczak-Radzimska and Jesionowski 2014), especially one-dimensional structures such as needles, ribbons, tubes, wires (Nikoobakht et al. 2013), rods (Jaisai et al. 2012), prisms (Wirunmongkol et al. 2013), sheets (Lu et al. 2017), triangles (Nagarajan and Kuppusamy 2013), squares (Mishra and Sharma 2015), and combs (Xu et al. 2012). Besides that, zinc oxide appears in twodimensional and three-dimensional structures. The two-dimensional structures including nanoplate and nanopellets while flower, dandelion, snowflakes, coniferous urchin-like and 
polygonal (Zhou et al. 2013; Namvar and Rahman 2013) are the zinc oxide shapes that are grouped in three-dimensional structures. The shape, size, and spatial structure can be tailored by adjusting methods during the preparation of zinc oxide. In general, three methods are applied to prepare zinc oxide: (1) chemical, (2) physical, and (3) biological. Controlled precipitation, the sol-gel method, solvothermal and hydrothermal methods, and the method using emulsion and microemulsion environments are categorized as chemical methods (Kolodziejczak-Radzimska and Jesionowski 2014). The biological method, which is regarded as a green method, uses substrates including plant extracts, microorganisms, enzymes, and bacteria.

The biological or green method in processing zinc oxide has attracted many researchers in biosensors, pharmaceuticals, cancer treatment, and magnetic resonance imaging (MRI) areas (Kulkarni and Muddapur 2014). This is due to its eco-friendly, nontoxic, and safe reagent that is preferred in the biologically mediated preparatory method compared to the chemical and physical methods (Bhuyan et al. 2015). In addition, efficiency in cost and synthesizing particles without pressure has led to truly green chemistry (Nagarajan and Kuppusamy 2013; Sutradhar and Saha 2015). Equation 1 shows the reaction in zinc oxide formation (Sutradhar and Saha 2015). A study conducted by Jamdagni et al. (2016) succeeded in producing 12 to $32 \mathrm{~nm}$ of zinc oxide particles in aggregates from Nyctanthes arbortristis (flower) extract. This occurred when a bioactive compound contained in biomaterial reduced the metal element to form metal oxide. In examples, this can successfully be achieved by gentle warming and incubation that could activate quinones in Cyprus sp. (mesophytes) to reduce its zinc oxide particle size (Kirthi et al. 2013). Algae, also known as bionanofactories, can be synthesized nanoparticles with high stability and important sources in producing metallic-nanoparticles (Ramaswamy et al. 2016). Macroalgae such as seaweeds that have become part of habitual diet in Asian countries can be classified into three subcategories: Phaeophyta (brown seaweed), Rhodophyta (red seaweed), and Chlorophyta (green seaweed) (Brownlee et al. 2012).

$$
\mathrm{Zn}^{2+}+2 \mathrm{e} \rightarrow \mathrm{Zn}^{0}+\operatorname{Air}\left(\mathrm{O}_{2}\right) \rightarrow \mathrm{ZnO}
$$

In manufacturing antibacterial paper, a coating technique is usually selected by incorporating antibacterial agent in coating film that is later coated on the paper surface. Another coating technique was applied by Akrami et al. (2015). The essential oils from cumin and a thyme-like plant that have antibacterial properties were extracted and applied on paper surfaces and presented good antibacterial activity against food-borne bacteria (Akrami et al. 2015). Prasad et al. (2010) also applied a coating technique and observed that no bacterial growth was observed for zinc oxide-coated paper. Other than the coating technique, an in situ bio-mediated precipitation method was also practiced. A study conducted by El-Samahy et al. (2017) produced antibacterial paper by incorporating chitosan and nanocellulose via in situ approaches that resulted in strong antibacterial activity of paper. In terms of applying inorganic material as antibacterial agent, Maślana et al. (2021) boosted antibacterial performance of their cellulose-based paper sheet by using titanium dioxide particles. In addition, Li et al. (2021) also focused on in situ growth of nano-ZnO/GQDs on their cellulose paper to repel against water and bacteria.

Bamboo is a member of a large woody grass family and is a fast-growing plant that can be found naturally in subtropics and temperate zones such as Asia. It is reported that bamboo can grow three times faster than eucalyptus with 1,300 to 1,400 species around the world (Liese and Kohl 2015; Yeasmin et al. 2015; Tripathi et al. 2018) with 120 species in Asia that include 59 species in Malaysia. The most common bamboo species such as 
Semantan (Gigantochloa scortechicinii) and Gading (Bambusa vulgaris) exhibit excellent strength capacity for building material compared to wood and concrete except concrete has better stiffness (Janssen 1981; van der Lugt et al. 2006; Dhanush et al. 2021). Other than being a good building material, a strong utensil, and current hygiene instrument as a toothbrush, bamboo is also an ideal material in papermaking (Chen et al. 2019; Hammett et al. 2001). Bamboo can be applied in producing advanced material such as antibacterial fabric. Zhang et al. (2013) improved antibacterial activity of bamboo fabric at $99 \%$ performance degree against $S$. aureus and $E$. coli by synthesizing zinc oxide. Another study conducted by Yin et al. (2017) improved the porosity properties of bamboo tissue paper's (napkins) surface by incorporating chitosan. In addition, Zhang et al. (2017) improvised bamboo antibacterial performance using zinc oxide and graphene oxide. The antibacterial bamboo is also expected to be a potential material in the textile industry.

Looking at the small number of studies that concentrated on the in situ bio-mediated preparation of zinc oxide, a study was conducted to be simpler in a single step and easier than the usual method. This study focused on the effect of precursor concentration, which is believed to be a great influencer to zinc oxide in situ performance.

\section{EXPERIMENTAL}

\section{Raw Materials and Chemicals}

The $2 \mathrm{~m}$ of Semantan bamboo culms (Gigantochloa scortechicinii) were purchased from Sungai Siput, Perak, Malaysia and ground into chips until 2 to $3 \mathrm{~cm}$ width and length. Air-dried algae of Rhodophyta were acquired from Semporna, Sabah, Malaysia. The chemicals involved in the study were zinc chloride $\left(\mathrm{ZnCl}_{2}\right)$, sodium hydroxide $(\mathrm{NaOH})$, sodium chlorite $\left(\mathrm{NaClO}_{2}\right)$, acetic acid $\left(\mathrm{CH}_{3} \mathrm{COOH}\right)$, and hydrogen peroxide $\left(\mathrm{H}_{2} \mathrm{O}_{2}\right)$. All chemicals were purchased from RandM Chemicals (Selangor, Malaysia).

\section{Preparation of Bleached Pulps of Bamboo}

These bamboo chips were cooked using a soda pulping technique with $17 \%$ sodium hydroxide in a twin digester (GIST, Daejeon, South Korea) at $170{ }^{\circ} \mathrm{C}$ for $90 \mathrm{~min}$. After completing the pulping process, the pulp was washed and screened using a Somerville Shive Content Analyser (Frank-PTI, Birkenau, Germany). The next step was the bleaching process, in which delignification (D) and extraction (E) processes as $\mathrm{D}_{1} \mathrm{EP}_{2} \mathrm{D}_{2}$ sequences were applied in a $70{ }^{\circ} \mathrm{C}$ water bath. The consistency of unbleached pulp was $10 \%$ which was placed in a transparent plastic bag containing $2.00 \%$ of $\mathrm{NaClO}_{2}$ and $3.00 \%$ of $\mathrm{CH}_{3} \mathrm{COOH}$ throughout the $\mathrm{D}_{1}$ stage for $180 \mathrm{~min}$. The bleaching process continued with the extraction step, in which a mixture of $\mathrm{NaOH}$ at $1.50 \%$ and $\mathrm{H}_{2} \mathrm{O}_{2}$ at $1.00 \%$ was applied to the pulps for $90 \mathrm{~min}$. Finally, the $\mathrm{D}_{2}$ stage involved the immersion of pulps for another 90 min by adding $\mathrm{NaClO}_{2}$ and $\mathrm{CH}_{3} \mathrm{COOH}$ at $1.25 \%$ and $3.00 \%$ concentrations accordingly. The pulps were washed between bleaching sequences. Prior to further experiment, the bleached pulp was beaten by using a PFI-mill Beater according to the TAPPI T248 (2000) standard method reaching 350 to $400 \mathrm{~mL}$.

\section{Pulp and Paper Characterization}

Approximately $500 \mathrm{~g}$ of dried algae was washed and oven-dried at $60{ }^{\circ} \mathrm{C}$ overnight. The dried alga was ground using a blender to obtain algae powder, which was then sieved with 40-mesh sifter to collect a uniform particle size. Later, $2 \mathrm{~g}$ of dried seaweed was heated with $200 \mathrm{~mL}$ of distilled water until it boiled before filtering it, of which the effluent was 
taken into the next experiment. The preparation of green zinc oxide nanoparticles via in situ approaches was conducted by incorporating $2.4 \mathrm{~g}$ of bleached pulps in the $100 \mathrm{~mL}$ of extract solution. Prior to that, the extract solution was prepared by adding different concentrations of pre-cursor, namely zinc chloride, and heated for $4 \mathrm{~h}$ at $50{ }^{\circ} \mathrm{C}$ in a water bath. Finally, the samples were rinsed with distilled water and proceeded to the papermaking by using handsheet machine. The papermaking process was referred to the TAPPI T205 (2006), producing a $60 \mathrm{~g} / \mathrm{m}^{2}$ piece of paper. The list of samples prepared in this study is shown as in Table 1.

Table 1. Samples Prepared for the Study

\begin{tabular}{|c|c|c|c|c|}
\hline Samples & B1 & B3 & B5 & B7 \\
\hline $\begin{array}{c}\text { Concentration of } \\
\text { Zinc Chloride }\end{array}$ & $0.1 \mathrm{M}$ & $0.3 \mathrm{M}$ & $0.5 \mathrm{M}$ & $0.7 \mathrm{M}$ \\
\hline
\end{tabular}

\section{Characterization of Zinc Oxide Nanoparticles and Zinc Oxide Paper}

The formation and distribution of zinc oxide on papers was observed using field emission scanning electron microscope (FESEM) (Model: JSM 7600F, JEOL, Tokyo, Japan). The energy dispersive X-ray (EDX) was applied to confirm the elements that attached on the fibers. The properties of zinc oxide-paper were characterized via X-ray dispersion (XRD) (PW 3040/60 MPD X'pert High Pro Panalytical, Phillips, Omaha, NE, USA) while antibacterial testing was conducted against three types of bacteria explicitly as Staphylococcus aureus (positive strain bacteria), Salmonella choleraesuis, and Escherichia coli (negative strain bacteria) using the agar well diffusion method (Balouiri et al. 2016).

\section{RESULTS AND DISCUSSION}

\section{Morphological Observation of Zinc Oxide Paper}

Morphological observation of zinc oxide paper is exhibited as micrographs shown in Fig. 1 via 500× 1,500×, and 10,000× magnifications. Flocs of elements were observed on the fiber surfaces of the papers. This was confirmed after spotting the elements using FESEM-EDX, which represented the elements of zinc and oxygen as shown in Fig. 2 and Table 2.

Table 2 exhibits scanning electron microscopy with energy dispersive X-ray (SEMEDX) analysis of the spotted area for two elements, namely $\mathrm{Zn}$ and $\mathrm{O}$, that appeared on paper surfaces. Figure 2 shows the percentage weight of zinc and oxygen for B1, B3, B5, and B7, which ranged from $15.08 \%$ to $34.08 \%$, and $17.45 \%$ to $32.59 \%$, respectively. Different weight, size, and shape of zinc oxide particles are the outcomes of interactions between bioactive compounds in algae like phenols, and metal atoms from precursor were added into the systems (Shao et al. 2004).

The zinc oxide particles were measured with a range of $400 \mathrm{~nm}$ to $570 \mathrm{~nm}$. They appeared in spherical form (Fig. 3), as achieved by Vinay and Chandrasekhar (2021), Vijayakumar et al. (2018) and Yedurkar et al. (2016). Chronologically, zinc oxide particles were synthesized by reducing $\mathrm{Zn}^{2+}$ from zinc chloride with the bioactive compounds present in algae extract (Sadatzadeh et al. 2018). After in situ preparation stage, the pulps were poured into the handsheet machine tank before filtering the pulp slurry to leave a sheet of paper on the wire mesh. Several parts of the elements of zinc oxide were believed to be flushed away, which researchers continue to find ways to protect as much zinc oxide 
from heavy dislodgements. As the findings of these preliminary experiments appear very beneficial, the retention of additives will be studied and applied in future experiments.
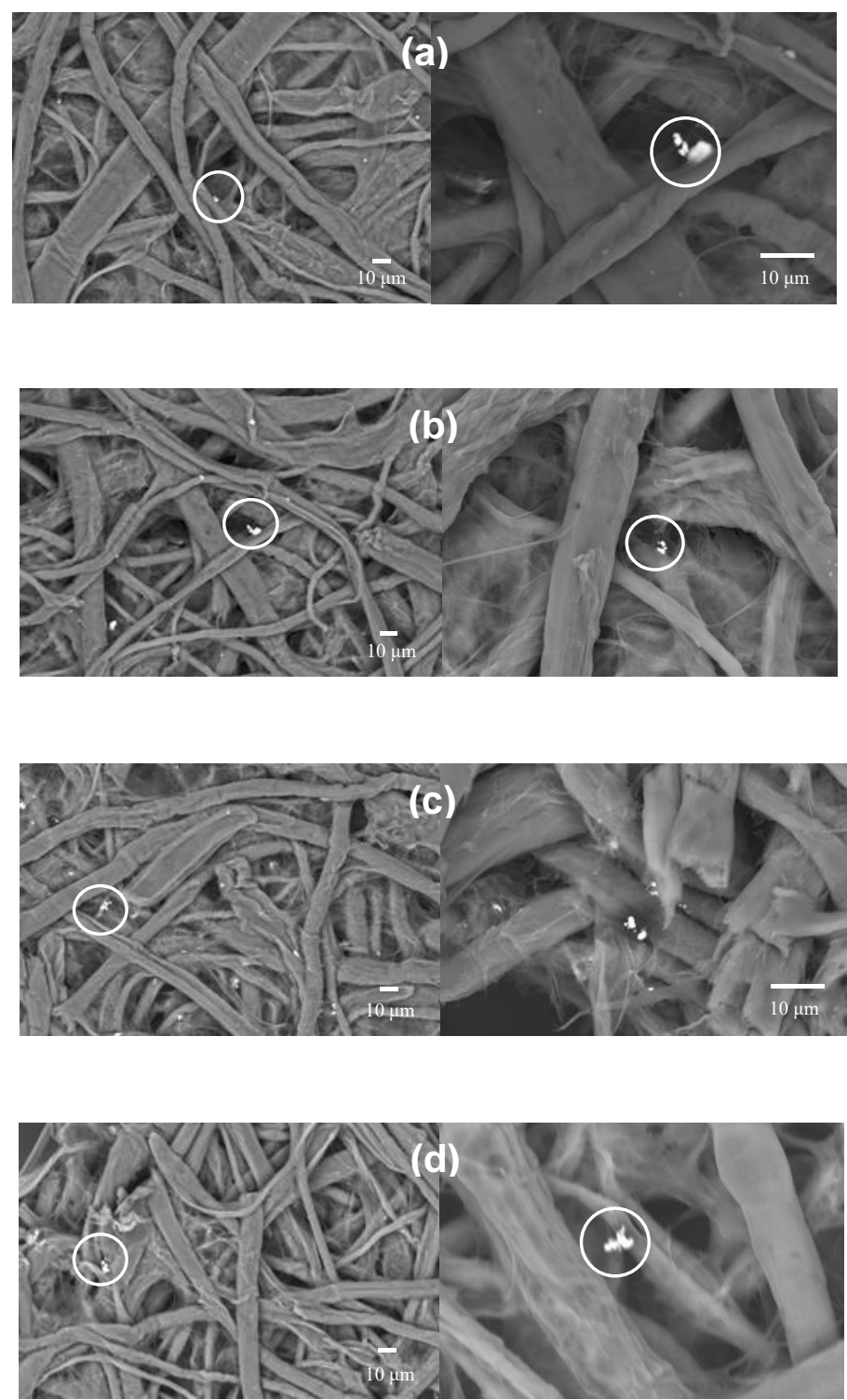

Fig. 1. FESEM micrographs of (a) B1, (b) B3, (c) B5, and (d) B7 with magnification of 500X (left column) and 1,500X (right column); the presence of zinc oxide is shown in the circles.

Table 2. SEM-EDX Analysis of Flocs in Terms of Two Elements that Appeared on Paper Surfaces

\begin{tabular}{|c|c|c|}
\hline \multirow{2}{*}{ Sample } & \multicolumn{2}{|c|}{ Percentage (\%) } \\
\cline { 2 - 3 } & Zinc & Oxygen \\
\hline B1 & 34.08 & 17.45 \\
\hline B3 & 23.75 & 17.72 \\
\hline B5 & 16.36 & 28.57 \\
\hline B7 & 15.08 & 32.59 \\
\hline
\end{tabular}




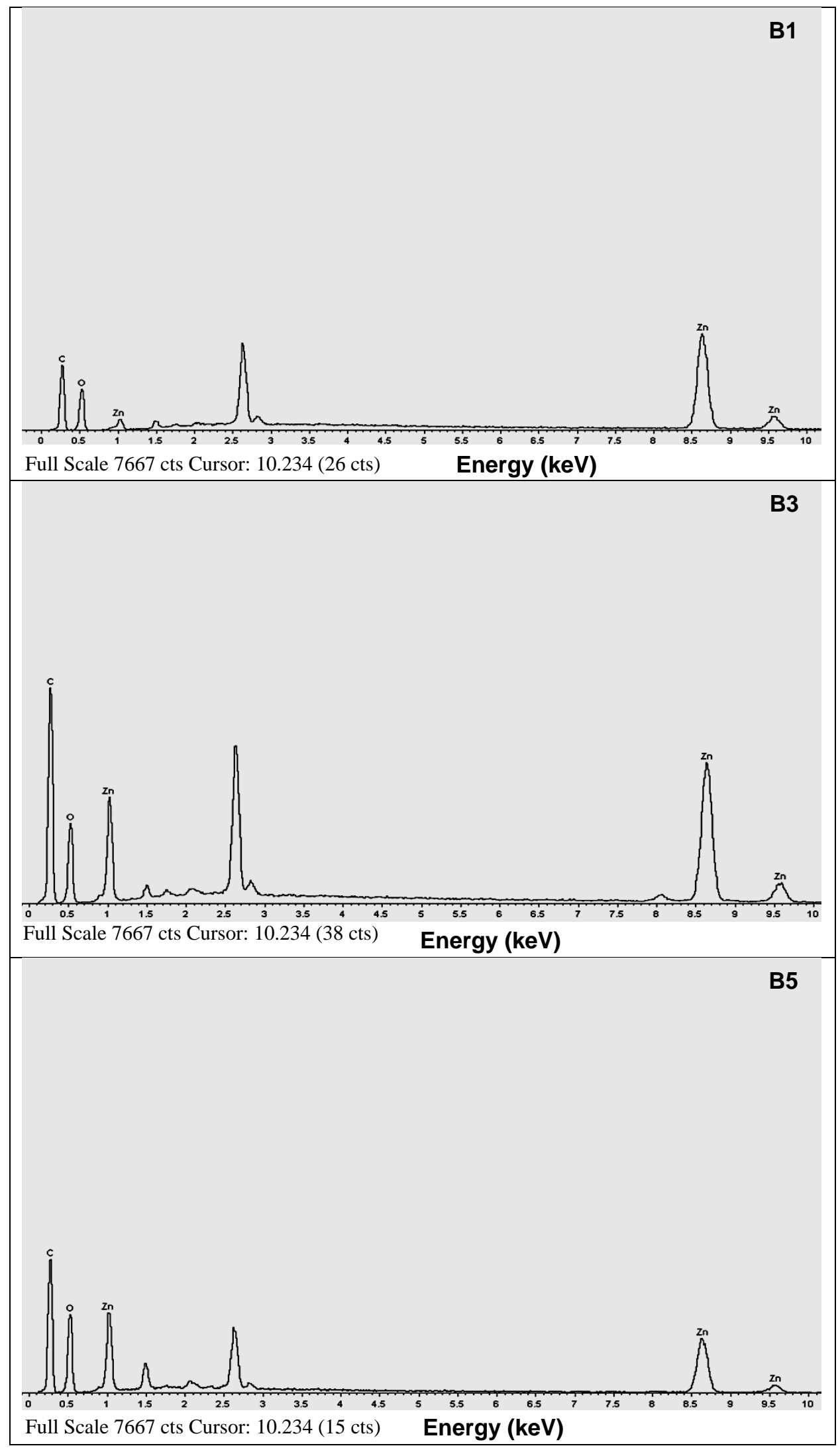




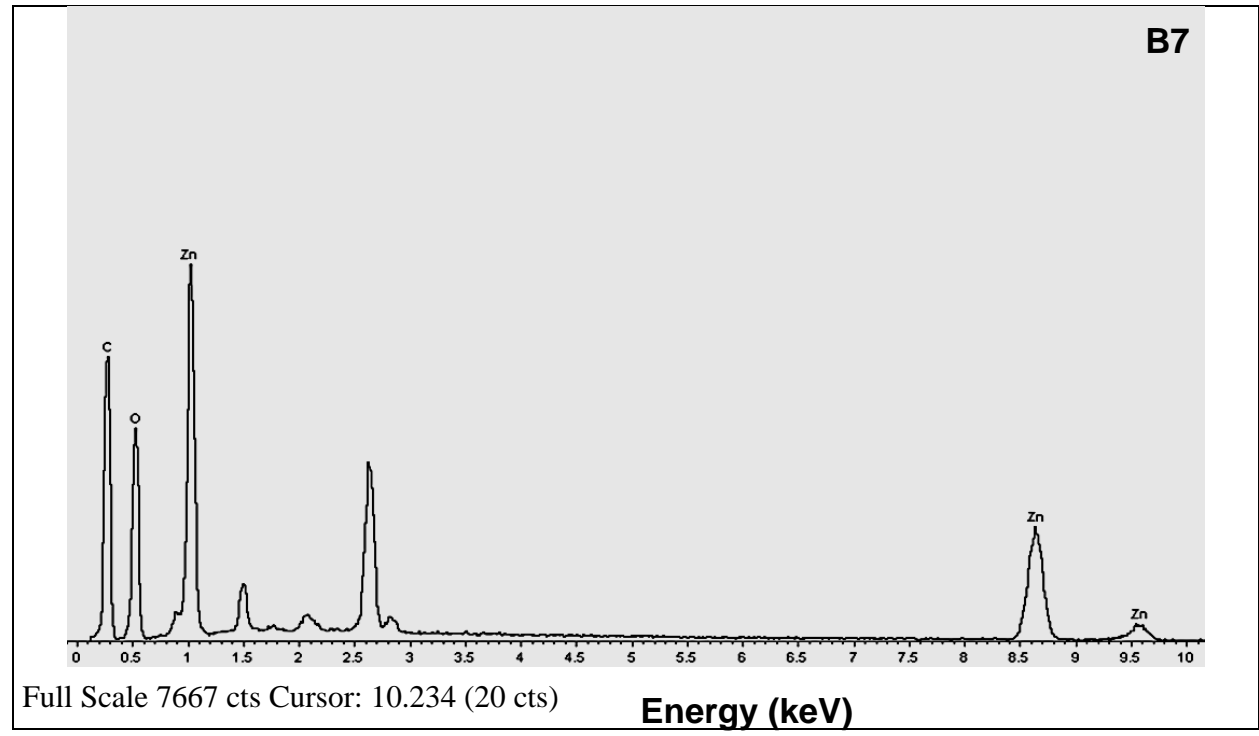

Fig. 2. SEM-EDX analysis of flocs in terms of two elements that appeared on paper surfaces

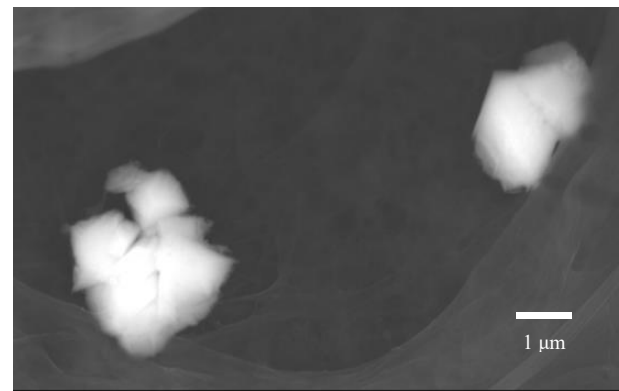

Fig. 3. Sample B3 of zinc oxide obtained in this study

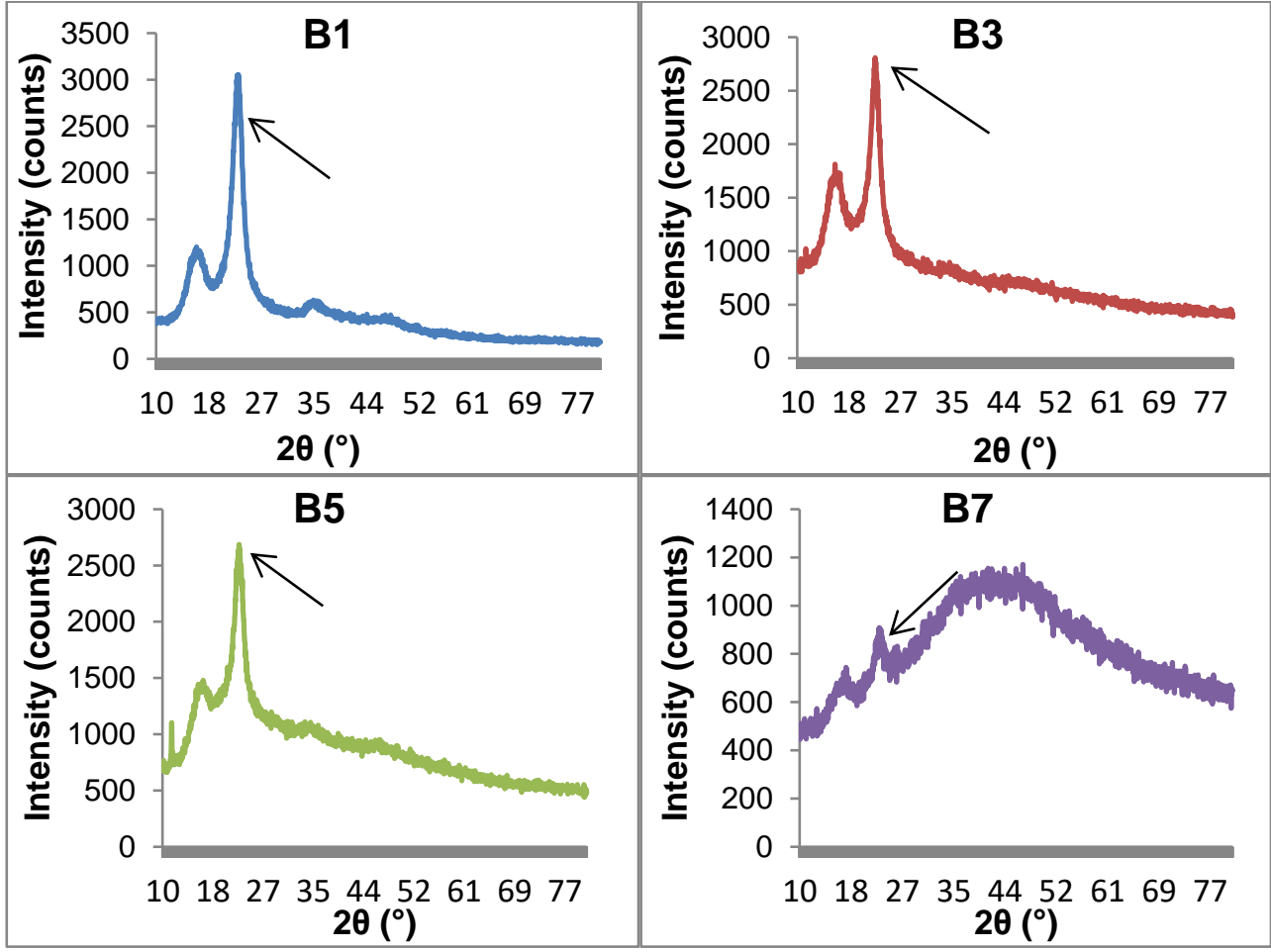

Fig. 4. The intensity peaks of crystalline structure of zinc oxide particles (shown by arrows) of samples B1, B3, B5, and B7 from XRD analysis 


\section{Chemical Composition of Zinc Oxide Pulp}

The zinc oxide pulp samples were dried in sheet form and were tested for their properties in terms of the crystalline structure of zinc oxide particles by using XRD. In Fig. 4 , sharp and narrow diffraction peaks of zinc oxide that attached on pulp were observed within the $2 \theta$ range from $10.00^{\circ}$ to $30.00^{\circ}$, which indicated high crystallinity of zinc oxide for samples B1, B3, and B5, as achieved by Prasad et al. (2010). The crystallinity of prepared zinc oxide pulp decreased as the concentration of zinc chloride increased. These were presented by sharp peaks observed at $22^{\circ}$ of $2 \theta$. Meanwhile, sample B7 only displayed a small peak at $22.2^{\circ}$, indicating a reduction of zinc oxide due to a decrease of degree of crystallinity (Ramesan et al. 2019). In addition, a broader diffraction pattern exhibited by sample B7 indicated the amorphous structure of zinc oxide was formed (Ramesan et al. 2018). This is also parallel to findings by Vijayakumar et al. (2018) and Chikkanna et al. (2019) who obtained green synthesized zinc oxide that is recorded at range $20^{\circ}<2 \theta>80^{\circ}$.

\section{Antibacterial Test}

Referring to Table 3, all samples exhibited inhibition zones from 10.00 to 25.00 mm. All zinc oxide pulp samples showed inhibition zones with increasing diameter as the concentration of the precursors increased. The average inhibition zone for pulp samples increased from sample B1 until B7 by $35 \%$ against $S$. aureus, $59 \%$ against $S$. choleraesuis, and $58 \%$ against E. coli. Sample B1 exhibited stronger antibacterial activity against $S$. aureus, while sample B3 successfully inhibited both $S$. aureus and S. choleraesuis. Meanwhile, samples B5 and B7 exhibited stronger antibacterial activities against $S$. choleraesuis with more than $20 \mathrm{~mm}$ of inhibition zone. Referred to findings by Alswat $e t$ al. (2016), parameter of concentration, increasing amount and decreasing particle size of zinc oxide contributed to inhibition zones. Interestingly, Gudkov et al. (2021) stated that modifying the synthesis method is one of the keys to increase antimicrobial effectiveness instead of the conventional method, namely as physicochemical.

According to Sidiqi et al. (2018), the size of zinc oxide nanoparticles tested against $E$. coli and $S$. aureus in the range from $401 \mathrm{~nm}$ to $1.2 \mu \mathrm{m}$ showed an increasing of antimicrobial activity as the size of particles decreased. The presence of zinc oxide particles as an antibacterial agent damaged the respiratory enzymes and cytoplasmic contents in the bacterial membrane, that resulted in the death of bacterial cells (Gunalan et al. 2012; Vijayakumar et al. 2018). The penetration properties of zinc oxide nanoparticles can be explained by reaction of the oxygen released on the zinc oxide surface with hydrogen ion to produce hydrogen peroxide that can penetrate and kill the bacteria (Fang et al. 2006; Gunalan et al. 2012). According to Ohira et al. (2008), the smaller size of zinc oxide enhanced the production of hydrogen peroxide that strongly depends on surface area of zinc oxide. Figure 5 shows the inhibition zones for B1, B3, B5, and B7 pulp samples against S. aureus, S. choleraesuis, and E. coli.

Table 3. Antibacterial Screening Test Results

\begin{tabular}{|c|c|c|c|}
\hline \multirow{2}{*}{ Sample } & \multicolumn{3}{|c|}{ Inhibition Zone (mm) } \\
\cline { 2 - 4 } & S. aureus & S. choleraesuis & E. coli \\
\hline B1 & 14.00 & 10.33 & 10.00 \\
\hline B3 & 18.33 & 18.33 & 16.33 \\
\hline B5 & 19.67 & 21.33 & 20.00 \\
\hline B7 & 21.67 & 25.00 & 23.67 \\
\hline
\end{tabular}



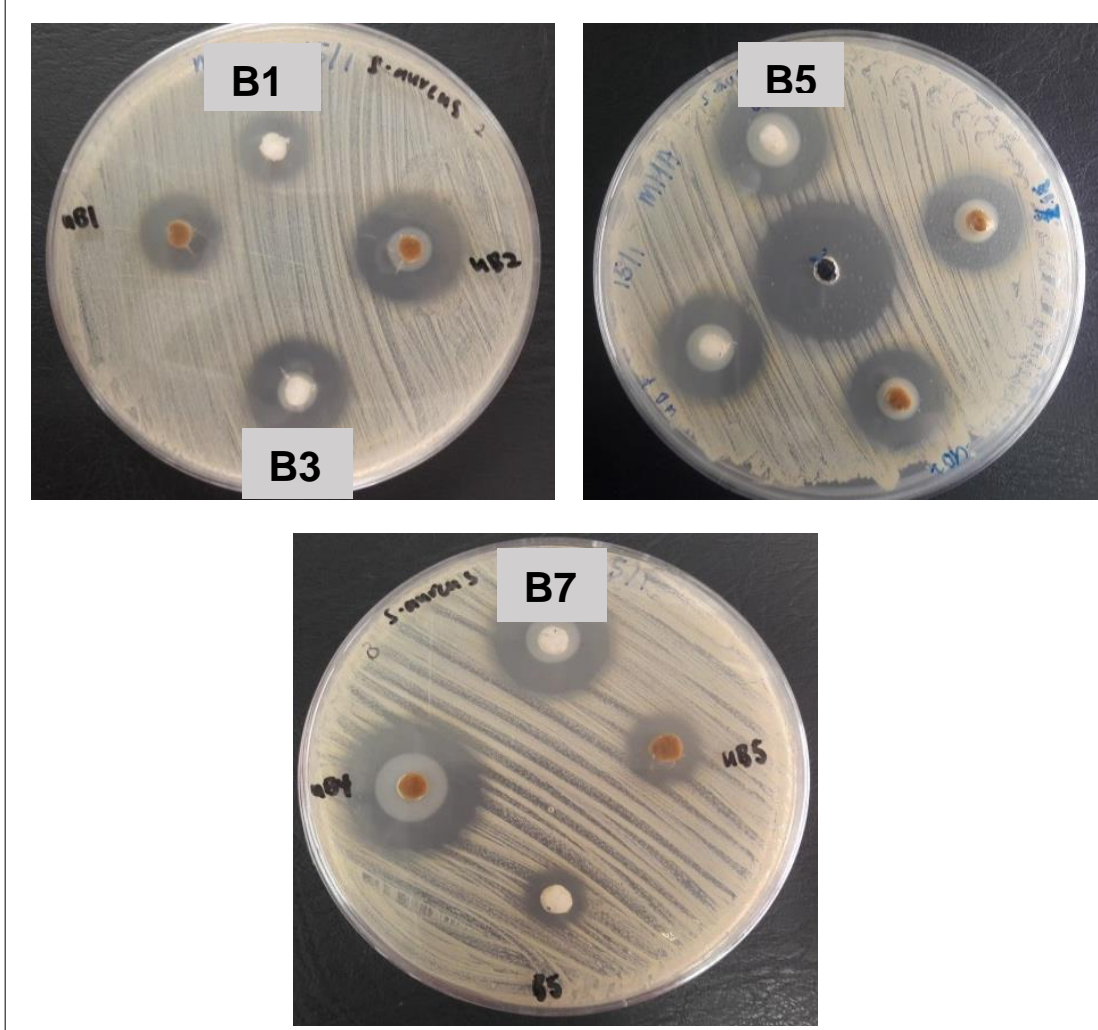

(a)
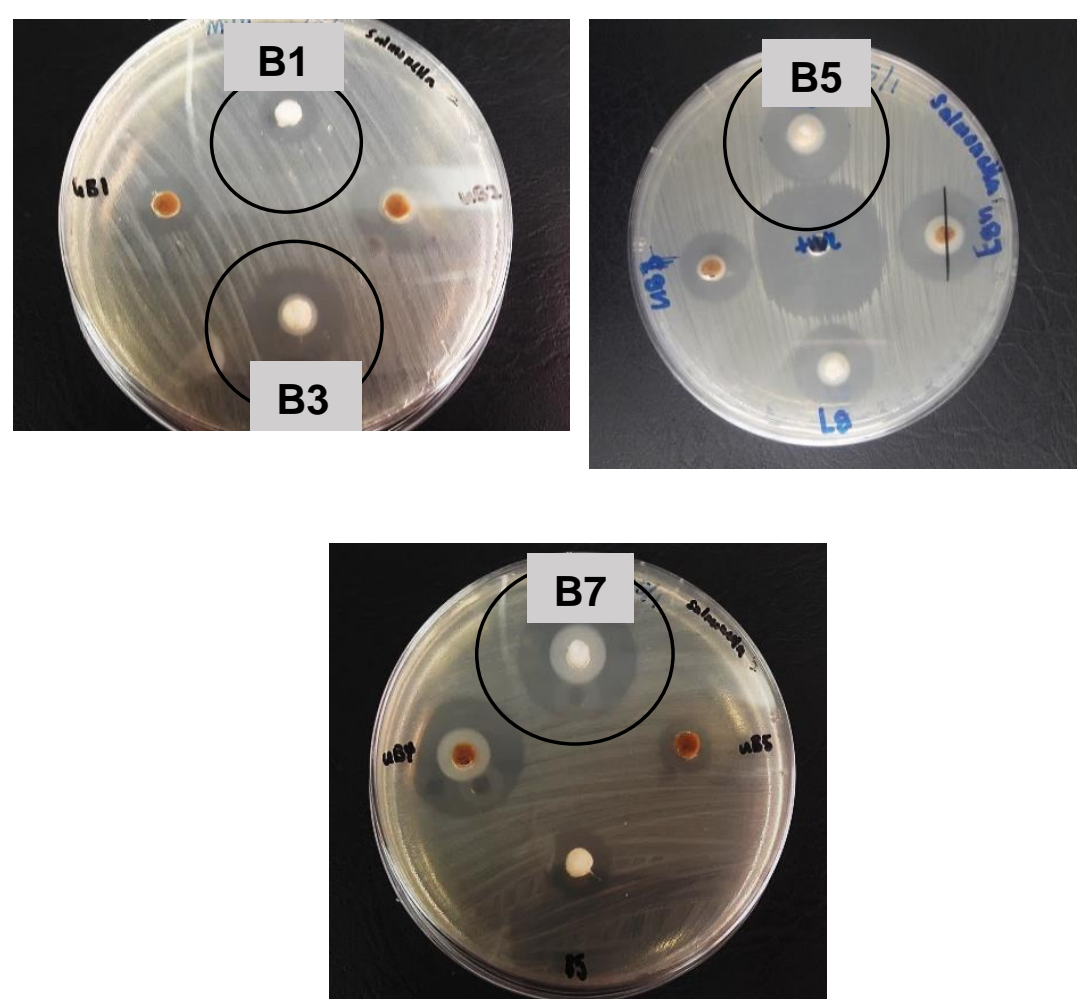

(b) 


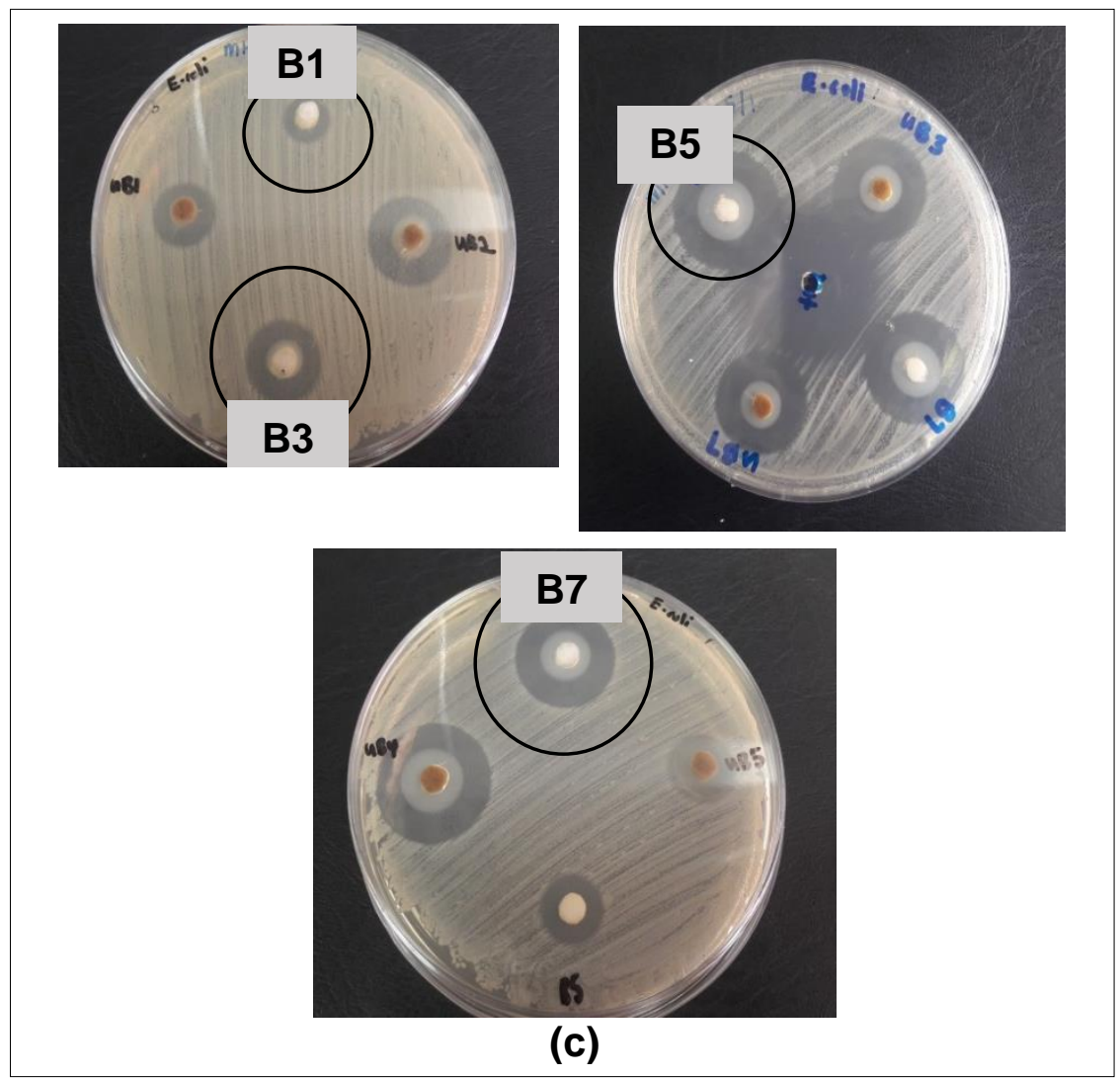

Fig. 5. Inhibition zone for samples B1, B3, B5, and B7 (black circles) against (a) $S$. aureus, (b) $S$. choleraesuis and (c) E. coli

\section{CONCLUSIONS}

Zinc oxide-containing paper was successfully produced via in situ approach, and the study can be concluded as follows:

1. Morphological observation showed that the size of the zinc oxide particles ranged from 400 to $570 \mathrm{~nm}$ with spherical shape. The percentages of element composition of the paper were $15.08 \%$ to $34.08 \%$ of zinc and $17.45 \%$ to $32.59 \%$ of oxygen.

2. The crystallinity of zinc oxide-pulp, prepared by a bio-mediated precipitation, decreased as the concentration of zinc chloride increased. The higher percentage of precursors developed more amorphous structure, as shown by B7.

3. Antibacterial activities against S. aureus, S. choleraesuis, and E. coli has shown acceptable inhibition regarding the increasing concentration of zinc chloride. It was found that more than a $30 \%$ increment of inhibition zone occurred with a diameter ranging from 10.00 to $25.00 \mathrm{~mm}$.

4. Overall, the addition of precursors more than $0.3 \mathrm{M}$ had higher potential to enhance the growth of zinc oxide via in situ preparation, hence providing better antibacterial resistance properties. 


\section{ACKNOWLEDGEMENTS}

The authors are grateful to Universiti Putra Malaysia for the financial support of this work under Putra Initiative Putra Grant Scheme vote no. 9662000 and Higher Institution Centre of Excellence (HICoE) vote no. 6369111.

\section{REFERENCES CITED}

Akrami, F., Rodríguez-Lafuente, A., Bentayeb, K., Pezo, D., Ghalebi, S. R., and Nerín, C. (2015). "Antioxidant and antimicrobial active paper based on Zataria (Zataria multi flora) and two cumin cultivars (Cuminum cyminum)," LWT-Food Sci. Technol. 60(2), 929-933. DOI: 10.1016/j.lwt.2014.09.051

Alswat, A. A., Ahmad, M. B., Saleh, T. A., Hussein, M. Z. B., and Ibrahim, N. A. (2016). "Effect of zinc oxide amounts on the properties and antibacterial activities of zeolite/ zinc oxide nanocomposite," Materials Science and Engineering: C 68, 505-511.

Balogun, S. W., James, O. O., Sanusi, Y. K., and Olayinka, O. H. (2020). "Green synthesis and characterization of zinc oxide nanoparticles using bashful (Mimosa pudica), leaf extract: A precursor for organic electronics applications," SN Applied Sciences 2(3), 1-8.

Balouiri, M., Sadiki, M., and Ibnsouda, S. K. (2016). "Methods for in vitro evaluating antimicrobial activity: A review," J. Pharm. Anal. 6(2), 71-79. DOI: 10.1016/j.jpha.2015.11.005

Belay, A., Mekuria, M., and Adam, G. (2020). "Incorporation of zinc oxide nanoparticles in cotton textiles for ultraviolet light protection and antibacterial activities," Nanomaterials and Nanotechnology 10, article no. 1847980420970052.

Bhuyan, T., Mishra, K., Khanuja, M., Prasad, R., and Varma, A. (2015). "Biosynthesis of zinc oxide nanoparticles from Azadirachta indica for antibacterial and photocatalytic applications," Mat. Sci. Semicon. Proc. 32, 55-61. DOI: 10.1016/j.mssp.2014.12.053

Brownlee, I. A., Fairclough, A. C., Hall, A. C., and Paxman, J. R. (2012). "The potential health benefits of seaweed and seaweed extract," in: Seaweed: Ecology, Nutrient Composition and Medicinal Uses, V. H. Pomin (ed.), Centre for Food Innovation, Sheffield Hallam University, Sheffield, England, pp. 2-3.

Chen, Z., Zhang, H., He, Z., Zhang, L., and Yue, X. (2019). "Bamboo as an emerging resource for worldwide pulping and papermaking," BioResources 14(1), 3-5.

Chikkanna, M. M., Neelagund, S. E., and Rajashekarappa, K. K. (2019). "Green synthesis of zinc oxide nanoparticles (ZnO NPs) and their biological activity," SN Applied Sciences 1(1), 1-10.

Dhanush, B. R., Hemanth Kumar, N. S., Bagur, A. G., Rajeev, A., and Sushma C. K. (2021). "A review on utilising bamboo as substitution for conventional building material," International Research Journal of Modernization in Engineering Technology and Science 3(1), 363-365.

El-Samahy, M. A., Mohamed, S. A. A., Abdel Rehim, M. H., and Mohram, M. E. (2017). "Synthesis of hybrid paper sheets with enhanced air barrier and antimicrobial properties for food packaging," Carbohyd. Polym. 168, 212-219. DOI: 10.1016/j.carbpol.2017.03.041

Fang, M., Chen, J.-H., Xu, X.-L., Yang, P.-H., and Hildebrand, H. F. (2006). "Antibacterial activities of inorganic agents on six bacteria associated with oral 
infections by two susceptibility tests," Int. J. Antimicrob. Ag. 27(6), 513-517. DOI: 10.1016/j.ijantimicag.2006.01.008

Gudkov, S. V., Burmistrov, D. E., Serov, D. A., Rebezov, M. B., Semenova, A. A., and Lisitsyn, A. B. (2021). "A mini review of antibacterial properties of $\mathrm{ZnO}$ nanoparticles," Front. Phys. 9, article no. 641481. DOI: 10.3389/fphy.

Gunalan, S., Sivaraj, R., and Rajendran, V. (2012). "Green synthesized ZnO nanoparticles against bacterial and fungal pathogens," Prog. Nat. Sci. 22(6), 693-700. DOI: $10.1016 /$ j.pnsc.2012.11.015

Hammett, A. L., Youngs, R. L., Sun, X., and Chandra, M. (2001). "Non-wood fiber as an alternative to wood fiber in China's pulp and paper industry," Holzforschung 55(2), 219-224. DOI: 10.1515/HF.2001.036

Jaisai, M., Baruah, S., and Dutta, J. (2012). "Paper modified with ZnO nanorods Antimicrobial studies," Beilstein J. Nanotech. 3(1), 684-691. DOI: 10.3762/bjnano.3.78

Jamdagni, P., Khatri, P., and Rana, J. S. (2016). "Green synthesis of zinc oxide nanoparticles using flower extract of Nyctanthes arbor-tristis and their antifungal activity," Journal of King Saud University - Science. DOI: 10.1016/j.jksus.2016.10.002

Janssen, J. J. A. (1981). Bamboo in Building Structures, Ph.D. Dissertation, Eindhoven University of Technology, Eindhoven, Netherlands. DOI: 10.6100/IR11834

Kirthi, A. V., Jayaseelan, C., and Rahman, A. A. (2013). "Biosynthesis and characterization of different nanoparticles and its larvicidal activity against human disease vectors," in: Marine Biomaterials: Characterization, Isolation and Applications, S.-K. Kim (ed.), CRC Press Taylor \& Francis Group, New York, NY, USA, pp. 273-287.

Kolodziejczak-Radzimska, A., and Jesionowski, T. (2014). "Zinc oxide-from synthesis to application: A review," Materials 7(4), 2833-2881. DOI: 10.3390/ma7042833

Kulkarni, N., and Muddapur, U. (2014). "Biosynthesis of metal nanoparticles: A review," Journal of Nanotechnology 2014, article ID 510246. DOI: 10.1155/2014/510246

Li, M., Feng, Q., Liu, H., Wu, Y., and Wang, Z. (2021). "In situ growth of nano$\mathrm{ZnO} / \mathrm{GQD}$ on cellulose paper for dual repelling function against water and bacteria," Materials Letters 283, article no.128838.

Liese, W., and Kohl, M. (2015). Bamboo: The Plant and Its Uses, W. Liese and M. Köhl (eds.), Springer International Publishing AG, Cham, Swirtzerland.

Lu, P., Zhou, W., Li, Y., Wang, J., and Wu, P. (2017). "Abnormal room temperature ferromagnetism in $\mathrm{CuO} / \mathrm{ZnO}$ nanocomposites via hydrothermal method," Applied Surface Science 399, 396-402. DOI: 10.1016/j.apsusc.2016.12.113

van der Lugt, P., van den Dobbelsteen, A. A. J. F., and Janssen, J. J. A. (2006). “An environmental, economic and practical assessment of bamboo as a building material for supporting structures," Constr. Build. Mater. 20(9), 648-656. DOI: 10.1016/j.conbuildmat.2005.02.023

Maślana, K., Żywicka, A., Wenelska, K. and Mijowska, E. (2021). "Boosting of antibacterial performance of cellulose based paper sheet via $\mathrm{TiO}_{2}$ nanoparticles," International Journal of Molecular Sciences 22(3), 1451.

Mirzaei, H., and Darroudi, M. (2017). "Zinc oxide nanoparticles: Biological synthesis and biomedical applications," Ceram. Int. 43(1), 907-914. DOI:

10.1016/j.ceramint.2016.10.051

Mishra, V., and Sharma, R. (2015). "Green synthesis of zinc oxide nanoparticles using fresh peels extract of Punica granatum and its antimicrobial activities," 
Spectrochimica Acta - Part A: Molecular and Biomolecular Spectroscopy 143(3), 158-164. DOI: 10.1016/j.saa.2015.02.011

Nagarajan, S., and Kuppusamy, K. A. (2013). "Extracellular synthesis of zinc oxide nanoparticle using seaweeds of gulf of Mannar, India," J. Nanobiotechnol. 11(39), 111. DOI: $10.1186 / 1477-3155-11-39$

Namvar, F., and Rahman, H. S. (2016). "Green synthesis, characterization, and anticancer activity of hyaluronan / zinc oxide nanocomposite," OncoTargets and Therapy 9, 4549-4559.

Nikoobakht, B., Wang, X., Herzing, A., and Shi, J. (2013). "Scalable synthesis and device integration of self-registered one-dimensional zinc oxide nanostructures and related materials," Chem. Soc. Rev. 42(1), 342-365. DOI: 10.1039/c2cs35164a

Ohira, T., Yamamoto, O., Iido, Y., and Nakagawa, Z. (2008). "Antibacterial activity of $\mathrm{ZnO}$ powder with crystallographic orientation," J. Mater. Sci.-Mater. M. 19(3), 14071412. DOI: $10.1007 / \mathrm{s} 10856-007-3246-8$

Osmond, G. (2019). "Zinc soaps: An overview of zinc oxide reactivity and consequences of soap formation in oil-based paintings," Metal Soaps in Art 2019, 25-46.

Prasad, V., Shaikh, A. J., Kathe, A. A., Bisoyi, D. K., Verma, A. K., and Vigneshwaran, N. (2010). "Functional behaviour of paper coated with zinc oxide-soluble starch nanocomposites," J. Mater. Process. Tech. 210(14), 1962-1967. DOI: 10.1016/j.jmatprotec.2010.07.009

Pronin, I. A., Kaneva, N. V., Bozhinova, A. S., Averin, I. A., Papazova, K. I., Dimitrov, D. T., and Moshnikov, V. A. (2014). "Photocatalytic oxidation of pharmaceuticals on thin nanostructured zinc oxide films," Kinetics and Catalysis 55(2), 167-171.

Rajendra, R., Balakumar, C., Ahammed, H. A. M., Jayakumar, S., Vaideki, K., and Rajesh, E. (2010). "Use of zinc oxide nano particles for production of antimicrobial textiles," International Journal of Engineering, Science and Technology 2(1), 202208.

Ramaswamy, S. V. P., Narendhran, S., and Sivaraj, R. (2016). "Potentiating effect of ecofriendly synthesis of copper oxide nanoparticles using brown alga: Antimicrobial and anticancer activities," B. Mater. Sci. 39(2), 361-364. DOI: 10.1007/s12034-0161173-3

Ramesan, M. T., Greeshma, K. P., Parvathi, K., and Anilkumar, T. (2019). "Structural, electrical, thermal, and gas sensing properties of new conductive blend nanocomposites based on polypyrrole/phenothiazine/silver-doped zinc oxide," J. Vinl. Addit. Techn. 26(2), 187-195. DOI: 10.1002/vnl.21732

Ramesan, M. T., Santhi, V., Bahuleyan, B. K., and Al-maghrabi, M. A. (2018). "Structural characterization, material properties and sensor application study of in situ polymerized polypyrrole/silver doped titanium dioxide nanocomposites," Mater. Chem. Phys. 211(6), 343-354. DOI: 10.1016/j.matchemphys.2018.02.040

Sadatzadeh, A., Charati, F. R., Akbari, R., and Moghaddam, H. H. (2018). "Green biosynthesis of zinc oxide nanoparticles via aqueous extract of cottonseed," Journal of Materials and Environmental Science 9(10), 2849-2853.

Shao, Y., Jin, Y., and Dong, S. (2004). "Synthesis of gold nanoplates by aspartate reduction of gold chloride," Chem. Commun. 10(9), 1104-1105. DOI: $10.1039 / \mathrm{b} 315732 \mathrm{f}$

Sutradhar, P., and Saha, M. (2015). "Synthesis of zinc oxide nanoparticles using tea leaf extract and its application for solar cell," B. Mater. Sci. 38(3), 653-657. DOI: 10.1007/s12034-015-0895-y 
TAPPI T205 (2006). "Forming handsheets for physical tests of pulp," TAPPI Press, Atlanta, GA, USA.

TAPPI T248 (2000). "Laboratory beating of pulp (PFI mill method)," TAPPI Press, Atlanta, GA, USA

Tripathi, S. K., Mishra, O. P., Bhardwaj, N. K., and Varadhan, R. (2018). "Pulp and papermaking properties of bamboo species Melocanna baccifera," Cellulose Chemistry and Technology 52(1-2), 81-88.

Vinay, S. P., and Chandrasekhar, N. (2021). "Structural and biological investigation of green synthesized silver and zinc oxide nanoparticles," Journal of Inorganic and Organometallic Polymers and Materials 31(2), 552-558.

Vijayakumar, S., Krishnakumar, C., Arulmozhi, P., Mahadevan, S., and Parameswari, N. (2018). "Biosynthesis, characterization and antimicrobial activities of zinc oxide nanoparticles from leaf extract of Glycosmis pentaphylla (Retz.) DC," Microb. Pathogenesis 116, 44-48. DOI: 10.1016/j.micpath.2018.01.00

Wirunmongkol, T., O-charoen, N., and Pavasupree, S. (2013). "Simple hydrothermal preparation of zinc oxide powders using Thai autoclave unit," Energy Procedia 34, 801-807. DOI: 10.1016/j.egypro.2013.06.816

Wu, J. J., Liu, S. C., Wu, C. T., Chen, K. H., and Chen, L. C. (2002). "Heterostructures of ZnO-Zn coaxial nanocables and ZnO nanotubes," Appl. Phys. Lett. 81(7), 1312-1314. DOI: $10.1063 / 1.1499512$

$\mathrm{Xu}, \mathrm{T} ., \mathrm{Ji}, \mathrm{P} ., \mathrm{He}, \mathrm{M}$., and Li, J. (2012). "Growth and structure of pure $\mathrm{ZnO}$ micro/ nanocombs," J. Nanomater. 2012, Article ID 797935. DOI: 10.1155/2012/797935

Yeasmin, L., Ali, N., and Gantait, S. (2015). "Bamboo: An overview on its genetic diversity and characterization," 3 Biotech 5, 1-11. DOI: 10.1007/s13205-014-0201-5

Yedurkar, S., Maurya, C., and Mahanwar, P. (2016). "Biosynthesis of zinc oxide nanoparticles using ixora coccinea leaf extract-A green approach," Open Journal of Synthesis Theory and Applications 5(1), 1-14.

Yin, Y., Dang, C., Zheng, X., and Pu, J. (2017). "Synthesis of 2-hydroxypropyl trimethylammonium chloride chitosan and its application in bamboo fiber paper," BioResources 12(2), 2899-2911. DOI: 10.15376/biores.12.2.2899-2911

Zhang, G., Liu, Y., Morikawa, H., and Chen, Y. (2013). "Application of ZnO nanoparticles to enhance the antimicrobial activity and ultraviolet protective property of bamboo pulp fabric," Cellulose 20(4), 1877-1884. DOI: 10.1007/s10570-013-9979-2

Zhang, J., Zhang, B., Chen, X., Mi, B., Wei, P., Fei, B., and Mu, X. (2017). "Antimicrobial bamboo materials functionalized with $\mathrm{ZnO}$ and graphene oxide nanocomposites," Materials 10(3), article no. 239. DOI: 10.3390/ma10030239

Zhou, Y., Liu, C., Li, M., Wu, H., Zhong, X., Li, D., and Xu, D. (2013). "Fabrication and optical properties of ordered sea urchin-like $\mathrm{ZnO}$ nanostructures by a simple hydrothermal process," Materials Letters 106, 94-96. DOI: 10.1016/j.matlet.2013.04.102

Article submitted: November 5, 2020; Peer review completed: February 6, 2021; Revised version received: June 5, 2021; Accepted: June 6, 2021; Published: July 20, 2021.

DOI: 10.15376/biores.16.3.6121-6134 